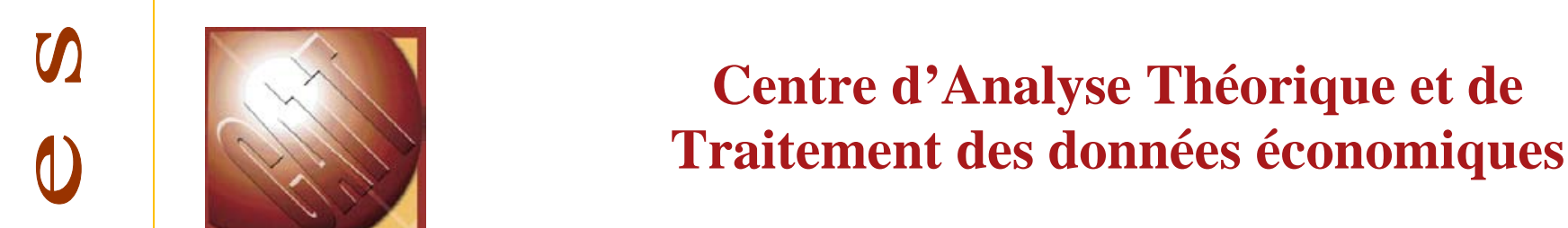

0

CATT WP No. 8 March 2016

HOW INCOME AND CROWDING EFFECTS INFLUENCE THE WORLD MARKET FOR FRENCH WINES

Fabien CANDAU Florent DEISTING Julie SCHLICK 


\title{
How Income and Crowding Effects influence the World Market for French Wines
}

\author{
Fabien CANDAU, Florent DEISTING, Julie SCHLICK
}

March 21, 2016

\begin{abstract}
Wine prices rose rapidly between 2001 and 2011 but have now stagnated. The growth phase could be explained by the increased demand from emerging markets while the subsequent stagnation may result from the crowding effect caused by the entry of numerous new varieties onto the wine market. The generalized model of ideal variety proposed by Hummels and Lugovskyy (2009) combines these two elements and focusing on French exporters, we find partial support for this explanation at the world level. A $1 \%$ increase in GDP per-capita (income effect) generated an increase in price of $1.13 \%$ between 2001 and 2011. In contrast a $1 \%$ increase in market size (competition effect) reduced prices by $1.10 \%$ over the same period. This paper goes further into the analysis of these effects by considering wine exports according to the mode of transport used and indirectly evaluates economies of scale when wine is exported by land, sea or air (via a gravity equation). Economies of scale are observed for transport by plane and ship but not for road. A $10 \%$ increase in the value of wine exported by road (plane) leads to a rise (reduction) in transport costs of $0.5 \%$ (19\%).
\end{abstract}

\section{Introduction}

What is the impact of per capita GDP growth on prices? On one hand, richer agents are more willing to pay high prices, but on the other hand richer markets attract more companies and this new competition can reduce prices. What is the net impact? Do firms generally set higher prices on richer markets? 
These questions are both significant and controversial in terms of international economics. In standard models of monopolistic competition with homothetic preferences (e.g. Krugman, 1980), the law of one price is verified ; markups, prices and the elasticity of demand are invariant to competition and income. The price of one type of goods differs between countries because of trade costs or preferences. In models with strategic interactions along a finite product space (e.g. Lancaster, 1979), more firms entering the market causes a "crowding effect", varieties become more substitutable and the price elasticity of demand, although invariant to income, increases with market size (i.e. competition). The empirical interpretation of this result is that, once we control for competition, the elasticities of the demand would be identical in rich and poor countries. The same result is obtained in models with heterogeneous firms and quasi-linear preferences ( e.g. Melitz and Ottaviano, 2008). In contrast, by extending the Lancasterian approach, Hummels and Lugovskyy (2009) propose a model where per capita GDP growth attracts more sellers, leads to more competition and forces firms to set lower prices. This result has been challenged by Simonovska (2015), both by proposing a new mode $!^{1}$ and also by controlling for transport costs in her empirical analysis. The fact of disregarding logistics companies, that apply lower transport costs to both richer and larger markets (according to economies of scale, competition) can bias the result. By working with 245 identical products sold exclusively on the Internet and by taking into account shipping prices, Simonovska (2015) finds that firms set higher prices for identical goods in richer destinations but are not influenced by the market size.

Our paper pursues these studies with two goals, the first is to use insight from this existing literature to analyse the wine market, the second is to use the wine market to test competing models of international economics. We use a unique dataset for 2001-2011 that reports bilateral export prices for French producers selling to all importers worldwide. The panel data structure makes it possible to identify price levels that are specific to an importer-product (taste, culture, etc) and price changes that are specific to an exporter-product (quality, etc) $2^{2}$ relating changes in prices over-time for

\footnotetext{
${ }^{1}$ Simonovska (2015) proposes a model with non-homothetic preferences from a hierarchic-choice of consumption (Jackson, 1984). In this model where the marginal utility is bounded (consumers may have zero demand for some varieties, see also Sauré, 2012), the relative price of a variety is higher in relatively richer markets which contradicts Hummels and Lugovskyy's (2009) results.

${ }^{2}$ The current paper is not interested in vertical differentiation i.e. we wish to control for the high price of wine on richer market due to the fact that rich importers demand goods of high quality. See Verhoogen (2008) and Fajgelbaum et al. (2011) for models of international trade focusing on product quality and more particularly Crozet, Head and Mayer (2012) on Champagne wine. See also Di Comite, Thisse and Vandenbussche (2014) for a model of vertical and horizontal differentiation applied to the
} 
an importer/exporter-product to changes in importer characteristics. While the Lancasterian approach has been applied in many hedonist studies on wine characteristics ${ }^{3}$ its extension by Hummels and Lugovskyy (2009) to analyse international wine trade has, to our knowledge, never been carried out. In comparison to the wine economics literature that distinguishes the relevance of various characteristics mainly in terms of supply: ${ }_{4}^{4}$ here we focus on determinants of demand. We confirm Hummels' and Lugovskyy's (2009) conclusion $5^{5}$ by finding that the price elasticity of demand is influenced by GDP per capita as well as importer GDP, contrasting with standard results based on monopolistic competition with homothetic preferences.6 The market size, approximated by importer GDP, has a negative effect on the price differential as well as on export share, revealing a competition effect on external markets for French producers.

While our data does not enable us to control for shipping costs as in Simonovska (2015), we do know the means of transport; trade flows can therefore be separated and analyzed in detail in order to reconcile standard models with the data. We show that a standard gravity equation performs poorly for the wine sector. However, we find that a more precise specification of trade costs helps to improve this performance. Imitating pro-competitive effects, it is possible that shipping prices react to change in market size. This change is due to economies (or dis-economies) of scale in transportation. With endogenous trade costs, an increase in income per-capita has a stronger impact on the trade of high quality wines exchanged under modes of transport with high economies of scale. We quantify to which degree wines exported by water and land benefit from a smaller income effect than wine exported by air. To our knowledge, such an analysis

\section{beer sector.}

${ }^{3}$ For instance to quote just a few contributions (see Cardebat, Figuet and Paroissien (2014) for a review), Nerlove (1995) discusses the standard hedonic price equation to study preferences of Swedish wine consumers, Combris, Lecocq and Visser (1997) apply this method to Bordeaux wines to analyze the impact of sensory characteristics (provided by a jury under blind tasting conditions) on prices, and Roma, Di Martino and Perrone (2013) use this method to explain the price of Sicilian wines.

${ }^{4}$ Ashenfelter (2008) updates its "Bordeaux wines equation" where prices are explained by weather conditions, wine age and expert judgments. See Storchmann (2011) for a survey on Ashenfelter's works and on recent developments in wine economics. Furthermore, by using data on endowments (e.g. soil qualities, weather conditions) as well as data on technology (such as manual operations e.g. picking and selecting grapes, the process of bottling wines, etc), Gergaud and Ginsburgh (2008) succeed in discriminating between determinants of quality (by using instrumental variables) in favor of technology.

${ }^{5}$ Hummels and Lugovskyy (2009, Table 2, p.16) test their predictions for thirty-eight 2-digit industries, including HS-code 22, "beverages, spirits and vinegar", which include wine.

${ }^{6}$ The most recent work in wine economics with CES preferences and monopolistic competition between heterogeneous firms is Crozet, Head and Mayer (2012). By working on Champagne wine, they justify the CES assumption by emphasizing that (in contrast to other wines studied here), producers blend several years of grapes to reproduce a constant quality over time. 
of export linked to transport has never before been studied in wine economics.

Our paper is in four parts. Firstly we give a brief introduction and presentation of our database. Secondly, by applying the Hummels and Lugovsky (2009) methodology, we show the empirical results for the wine sector. Thirdly, we analyse alternative models and show our investigations into the role of (dis)economies of scale in wine transport. Finally we draw our conclusions.

\section{$2 \quad$ Data and preliminary results}

In this section, we briefly present our data set and our first results based on the Generalized Model of Ideal Variety (GMIV) proposed by Hummels and Lugovskyy (2009).

\subsection{Data description}

Our data set on wine exports comes from the Single Administration Declarations (SAD) concerning the period 2001-2011, collected by the French customs and assembled by INSEE. The monthly database reports wine exports, mode of transport, exporters on each market at the 8-digit Harmonized System. Such a large database of French wine has never been used up to now 7

This database contains the SIREN number that allows each exporter to be identified (address and economic features of each unit). We match this database with the SIREN register and we only retain firms found under the label "culture" that includes wine producers. The value and volume of each product are reported monthly, we compute the sum annually, by product, exporter and destination market. This database also contains information concerning the mode of transport. More precisely we know at the individual level and for each destination market if the wine has been exported by plane, boat, road, rail, river, postal services or by private mode..$^{8}$

Road was the dominant mode of transport prior to 2009, but while this mode of transport remains stable, transport by boat has more than doubled during the period, both in value and in volume, now representing the main mode of transport. This rise can certainly be explained in part by decreasing shipping costs but it can also reflect changes in the destination market.

\footnotetext{
${ }^{7}$ Many articles work on particular wines, e.g. Crozet et al. 2012 on Champagne (and red Burgundy as a robustness check), and do not take into account mode of transportation.

${ }^{8}$ Rivers, postal and private modes are marginal.
} 
Export by plane has sharply increased, particularly in terms of value. For instance the value of red Bordeaux wines exported by plane has soared and is 10 times higher than in 2001. In contrast the volume of Bordeaux exported by plane has remained constant, revealing a striking increase of the unit value of this wine that cannot simply be explained by an increase in quality. Moreover this increase in the value of wine masks contrasting price-setting in destination markets. Figure (1) plots the value of red Bordeaux exported by air with respect to GDP per capita of destination countries. For each year, a positive correlation can be observed. The cross-country variation in price seems directly related to GDP per capita. However if we now compare pricechanges over a particular time-period for a particular importer with changes in the countries' GDP per capita, very different results can be observed. The price of wine sold in China strongly increased between 2001 and 2011, while in Brazil, a country also with a strong growth in terms of GDP per capita, the value of Bordeaux wine exported stagnated. In Argentina, a country that developed over that period to become the fifth world wine producer, the nominal exportation of Bordeaux even declined.

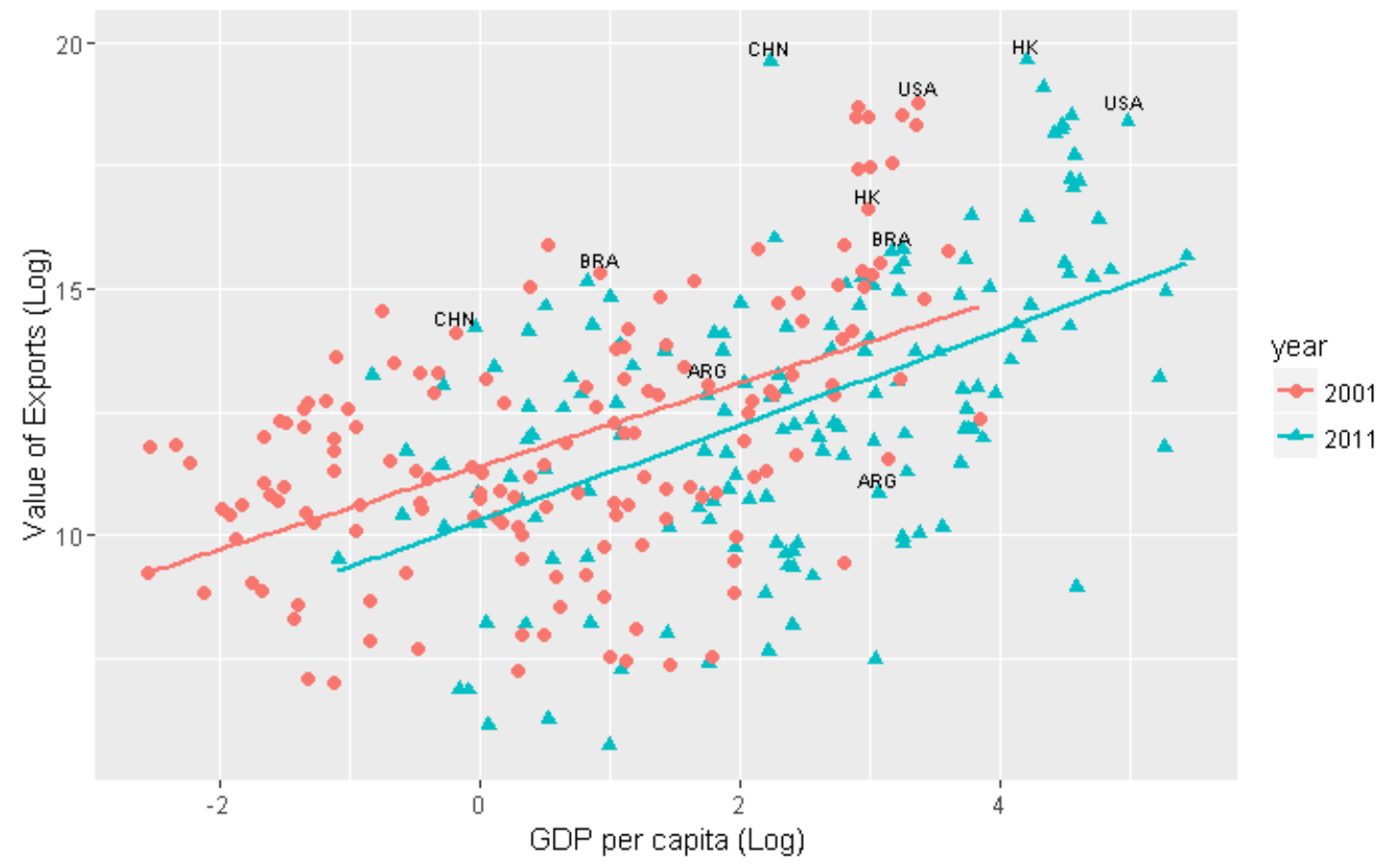

Figure 1: Bordeaux wine (exported by air) and GDP per capita 


\subsection{Generalized Model of Ideal Variety (GMIV)}

The index Fine Wine 1000 (representing 80\% of the world wine market by price) increased two and a half fold between 2001 and 2010 is now stable at around 4 billion dollars (Millar, 2014). Income effect and competition may explain this result. Chevet, Lecocq and Visser (2011) certainly have in mind the former effect when they write that "the sky-high price paid for the 2009 vintage can in large part be attributed to increased wine demand from Asia (China in particular)". However such a claim is not investigated in detail in Chevet et al. (2011) who focus on the impact of weather conditions on historical price data. In order to analyse these effects, we follow the empirical analysis proposed by Hummels and Lugovskyy (2009) to test their Generalized Model of Ideal Variety (GMIV).

According to the GMIV model, two opposing effects related to income and income per-capita are crucial to the analysis of trade elasticities. On one hand, a rise of income generates more demand and the entry of new varieties. This leads to more competition between firms which proceed to reduce their mark-ups in order to stay in the market. Ceteris paribus, there are lower prices in larger markets.

On the other hand, consumers are increasingly "finicky" regarding the gap between current consumption and the ideal variety when consumption of a typical variety increases. Consequently, the richer the consumer, the more they appreciate value of a variety that is close to the ideal. This reaction encourages firms to set higher prices. All else being equal (in particular market size), firms set higher prices when consumers are richer. While the market size generates a pro-competitive effect, increasing price elasticity, rising income per worker reduces this elasticity.

To capture these opposed effects in the wine sector we consider that changes in the price set by a French producer $j$ on a product $k$ in the country $i$ at time $t$ depends on destination GDP and GDP per capita:

$$
\ln \frac{p_{i j, t}^{k}}{p_{i j, t-1}^{k}}=a_{0}+a_{1} \ln \frac{Y_{i, t}}{Y_{i, t-1}}+a_{2} \ln \frac{Y_{i, t} / L_{i, t}}{Y_{i, t-1} / L_{i, t-1}}+f_{j}+f_{k}+\epsilon_{i j, t}^{k} .
$$

where $Y_{i}$ measures the market size of the partner country $i$, approximated by GDP, and $L_{i, t}$ the population (GDP and population statistics are from the WDI database). A negative coefficient $\widehat{a_{1}}$ is expected to confirm that the market size reduces price due to a competition effect that increases price elasticity. In contrast, a positive coefficient $\widehat{a_{2}}$ confirms that, depending on market size, a rise in GDP per capita increases prices 
due to the income effect (that reduces price elasticity). Fixed effects at the product and firm level are introduced to control for cost and quality variations. We do not introduce destination fixed effects which would control for variations that are specific to importers. In fact these effects would capture the effect of economic growth of the partners we intend to measure. In other words, we exploit cross-importer variation to assess the income and competition effect.

Table (1) reports results. Column 1 explains price growth over the whole period by only using extrema of the period, i.e. years 2001 and 2011. Column 2 uses price differential yearly (2011-2010, 2010-2009, and so on). Year fixed effects are introduced for estimations reported in the last Column.

\begin{tabular}{ccc} 
& $\begin{array}{c}\text { Price differential } \\
\text { (using years 2001 and 2011) }\end{array}$ & $\begin{array}{c}\text { Yearly price differential } \\
(2001-2011)\end{array}$ \\
\hline GDP per capita & 1.13 & 0.55 \\
GDP & $(0.498)^{b}$ & $(0.160)^{a}$ \\
& -1.10 & -0.49 \\
Year fixed effect & $(0.481)^{b}$ & $(0.158)^{a}$ \\
Product fixed effect & No & Yes \\
Firm fixed effect & Yes & Yes \\
R-square & Yes & Yes \\
Obs & 0.587 & 0.091 \\
& 3281 & 106508
\end{tabular}

OLS Estimations (RSE in brackets) a: significant at 1\%, b: at 5\%. All variables are in Log.

Table 1: Price regressions of French wines, 2001-2011

Whatever the period considered, Table (1) supports the conclusion of the GMIV. Income per capita fosters prices, while market size impacts negatively on the price differential. Using exporters and product fixed effects and exploiting time series variation in importer characteristics, we find that prices fell with importer GDP growth but rose with importer GDP per capita. A 1\% increase in GDP per-capita generated an increase in price of $1.13 \%$ between 2001 and 2011, while a $1 \%$ increase in market size reduced prices by $1.10 \%$ over the same period. In Appendix A we show that these results hold at a more disaggregated level (i.e. at the French regional level distinguishing wines by reputation). Additional robustness checks were performed here, including changes in variables capturing the income and market size effect. $9^{9}$ The model seems more pertinent

\footnotetext{
${ }^{9}$ For instance, following Simonovska (2015) we have also used population instead of GDP. While this variable appears insignificant in her analysis we find a coefficient of -0.743 significant at $1 \%$.
} 
for a long term analysis than over a short period of time, explaining almost $60 \%$ of the average price variations between 2001 and 2011, while only 10\% per year on average.

\section{Competing theories}

The above result illustrates that the main predictions of the GMIV models are confirmed for the wine sector. Here we go beyond this first step to discriminate between this model and more standard models of international trade. To illustrate this we consider the gravity equation proposed by Markusen (2010) (see also Frankel, Stein and Wei, 1998):

$$
x_{i j}^{k}=\left(Y_{j} Y_{i}\right)^{\alpha}\left(\frac{Y_{j}}{L_{j}} \frac{Y_{i}}{L_{i}}\right)^{\beta} \frac{\tau_{i j}^{1-\sigma}}{P_{i} P_{j}} .
$$

Where $Y_{i}$ and $Y_{j}$ are incomes (GDPs), $L_{i}$ and $L_{j}$ are the populations in $i$ and $j, P_{i}$ and $P_{j}$ are price indices, $\tau_{i j}$ represents bilateral trade costs and $\sigma$ is the elasticity of substitution between two varieties. With $\alpha=1$ and $\beta=0$ the gravity equation is similar to that obtained in Anderson and van Wincoop (2003) and Krugman (1980), there is no income effect, in contrast with $\beta \neq 0$ by which luxury and goods of basic necessity can be analysed.

To discriminate between this general equation and the GMIV prediction, we simply have to use this formula to compute imports of the rest of the world from $j$, i.e. $x_{r j}^{k}$ :

$$
x_{r j}^{k}=\left(Y_{j} Y_{r}\right)^{\alpha}\left(\frac{Y_{j}}{L_{j}} \frac{Y_{r}}{L_{r}}\right)^{\beta} \frac{\tau_{r j}^{1-\sigma}}{P_{r} P_{j}}
$$

and we use this expression to compute the trade-share $s_{i j}^{k}$, which is the $i$ 's import from $j$ on imports of the rest of the world, $r$ from country $j$. Taking the logarithm of this share finally provides the following equation:

$$
\ln s_{i j}^{k} \equiv \ln \frac{x_{i j}^{k}}{x_{r j}^{k}}=(1-\sigma) \ln \tau_{i j}+\ln \frac{Y_{i}^{\alpha+\beta}}{P_{i} L_{i}^{\beta}}+\ln \frac{P_{r} L_{r}^{\beta}}{Y_{r}^{\alpha+\beta}} \tau_{r j}^{\sigma-1}
$$

The interesting feature of this computation is that all the variables specific to French producers have been eliminated. Moreover, by using partner-product fixed effects, denoted by $f_{i}^{k}$, we can capture specific characteristics of importers (GDP per capita, price index, etc). In short, taking the logarithm of (3) using (2) enables the following 
equation to be estimated:

$$
\ln \left(s_{i j}^{k}\right)=(1-\sigma) \ln \left(\tau_{i j}\right)+f_{i}^{k}+\epsilon_{i j}^{k}
$$

The only variables that explain $s_{i j}^{k}$ are trade $\operatorname{costs} \tau_{i j}$ approximated by bilateral distance $d_{i j}$. This result contrasts with the GMIV model, where the distance to the market depends on the number of competitors, which itself varies according to GDP and GDP per-capita. Thus, by introducing distance in interaction with other variables, Hummels and Lugovskyy (2009) obtain what they call "a test of the CES null hypothesis":

$$
\ln s_{i j, t}^{k}=a_{0}+a_{1} \ln d_{i j}+a_{2} \ln d_{i j} \ln \left(Y_{i, t}\right)+a_{3} \ln d_{i j} \ln \left(Y_{i, t} / L_{i, t}\right)+f_{i}^{k}+\epsilon_{i j, t}^{k} .
$$

To validate the CES model (and also other models where GDP per-capita enters in a multiplicative form as we have shown), only the coefficient of distance should be significant (with $a_{2}=a_{3}=0$ Equation (3) is reduced to Equation (4) obtained from the general gravity equation).

They find that $\widehat{a_{2}}<0$ and $\widehat{a_{3}}>0$ are statistically significant, which validates their model. We have applied this methodology to our database. Geographical distance between countries is taken from the CEPII database. Table (2) illustrates results. Column 1 is the benchmark with similar independent variables to those used in the previous section (GDP and GDP per capita) in interaction with distance. 
dep var:

Share of trade

\begin{tabular}{|c|c|c|c|c|c|}
\hline Distance & $\begin{array}{c}-1.004 \\
(0.011)^{a}\end{array}$ & $\begin{array}{c}-1.115 \\
(0.026)^{a}\end{array}$ & $\begin{array}{c}-0.938 \\
(0.019)^{a}\end{array}$ & $\begin{array}{c}-1.580 \\
(0.135)^{a}\end{array}$ & $\begin{array}{c}-0.054 \\
(0.015)^{a}\end{array}$ \\
\hline GDP*Distance & $\begin{array}{c}0.032 \\
(0.000)^{a}\end{array}$ & $\begin{array}{c}0.037 \\
(0.001)^{a}\end{array}$ & $\begin{array}{c}0.031 \\
(0.001)^{a}\end{array}$ & & \\
\hline GDP per capita*Distance & $\begin{array}{c}0.010 \\
(0.001)^{a}\end{array}$ & & & & $\begin{array}{c}0.020 \\
(0.001)^{a}\end{array}$ \\
\hline Income share of top $10 \% *$ Distance & & $\begin{array}{c}0.797 \\
(0.069)^{a}\end{array}$ & & $\begin{array}{c}0.474 \\
(0.037)^{a}\end{array}$ & \\
\hline Income share of top $1 \% *$ Distance & & & $\begin{array}{c}0.710 \\
(0.019)^{a}\end{array}$ & & \\
\hline Production*Distance & & & & $\begin{array}{c}-0.018 \\
(0.002)^{a}\end{array}$ & $\begin{array}{c}-0.002 \\
(0.000)^{a}\end{array}$ \\
\hline R-square & 0.368 & 0.386 & 0.388 & 0.572 & 0.328 \\
\hline Obs & 203375 & 111383 & 113383 & 8751 & 67489 \\
\hline
\end{tabular}

Table 2: Share of trade and wealth

To validate the CES model, distance must be the only significant coefficient, which is clearly not the case here. These results disqualify the CES assumption used with a simple model of monopolistic competition ${ }^{10}$ Interactions between distance, market size and GDP per capita are essential in order to explain the share of wine exported as predicted by the GMIV model.

As a robustness check we have also used alternative measures of GDP per capita taking into account the income effect (Column 2 and 3). We have chosen specificially the top income shares (top $10 \%$ and top 1\%) from the World Top Incomes Database ${ }^{11}$, to identify how exportations evolved in richer markets. This variable seems more appropriate than GDP per capita for countries like China where consumption and investment ${ }^{12}$ in wine are concentrated at the top of the distribution. Results obtained with top income shares in Column 2, 3 and 4 of Table (2) confirm results obtained with GDP per capita and thus provide additional evidence supporting the GMIV model predictions.

\footnotetext{
${ }^{10}$ This does not disqualify CES preferences used with more sophisticated models of monopolistic competition, in particular those using heterogeneous firms.

${ }^{11}$ Alvaredo, Facundo, Anthony B. Atkinson, Thomas Piketty and Emmanuel Saez, The World Top Incomes Database, http://topincomes.g-mond.parisschoolofeconomics.eu/

${ }^{12}$ Dimson, Rousseau, and Spaenjers (2015) for instance wrote that "among wealthy individuals, fine wine is a mainstream investment" and Barclays (2012) reports that wine represents $2 \%$ of the wealth of about one quarter of high-net-worth individuals around the world that own a wine collection.
} 
Using other variables (based on income instead of share) we obtained similar results. ${ }^{13}$ Lastly Column 4 and 5 use the wine production in the destination market to test the robustness of our result regarding the competition effect. Once again, the interaction with distance is significant.

\section{Non-homothetic preferences and trade costs}

Surprisingly the GMIV has a better predictive power than alternative models based on the widely-used standard/powerful gravity equation (2). Consequently we return to this equation and after rearrangement and by taking the log of (2) we obtain the following expression:

$$
\ln \left(x_{i j}^{k}\right)=(\alpha+\beta) \ln \left(Y_{j} Y_{i}\right)-\beta \ln \left(L_{j} L_{i}\right)+(1-\sigma) \ln \left(\tau_{i j}\right)+\ln \left(P_{i} P_{j}\right)
$$

From this we estimate the following equation by separating wines exported by air, water and land:

$$
\ln \left(x_{i j, t}^{k}\right)=a_{1} \ln \left(Y_{j, t} Y_{i, t}\right)+a_{2} \ln \left(L_{j, t} L_{i, t}\right)+a_{3} \ln \left(\tau_{i j t}\right)+a_{4} \ln \left(P_{i t} P_{j t}\right)+\epsilon_{i j t}^{k}
$$

We expect to obtain support for non-homothetic preferences with a positive impact of GDP per capita for wine exported by air. These wines may be of better quality than wine exported via other transport systems and consequently may be more sensitive to GDP per capita. The crucial coefficient is that of population; indeed with a negative sign, $\widehat{a_{2}}<0$ we verify that $\beta>0$ and thus the gravity equation (2).

To control for price index, we refer to a wide range of literature using consumer price indices (e.g. Bergstrand, 1989; Baldwin and Taglioni, 2014). We carried out many robustness checks concerning this last variable. ${ }^{14}$

\footnotetext{
${ }^{13}$ One can observe that measures of income inequalities are related to the GMIV model, for instance Bekkers, Francois and Manchin (2012) generalize the Lancaster model more by considering that the compensation function is not only dependent on the consumption of a variety (as Hummels and Lugovskyy, 2009) but on total consumption. They then demonstrate that the elasticity of trade decreases with an Atkinson index of income inequality.

${ }^{14}$ Anderson and van Wincoop (2003) and Baldwin and Taglioni (2007) recommended the setting of partner-fixed effects to control for price index and to obtain an unbiased coefficient of distance (and border effects). These fixed effects have been used here and provide similar results to the consumer price index. However, because our main interest lies in GDP and population (and not in dyadic variables such as distance) it seems logical to remove these fixed effects. This is also the empirical strategy adopted by Baldwin and Taglioni (2011) who write: 'If the econometrician is only interested in estimating
} 
Furthermore, estimating the gravity equation by type of transport allows us to partially treat heterogeneity in terms of both products and destination markets. A selection effect linked to distance and to product quality certainly leads to the choice of one mode of transport rather than another. We have considered a standard form for trade costs:

$$
\tau_{i j t}=\operatorname{dist}_{i j} e^{b_{i j}}
$$

where $b_{i j}$ includes "dummies" representing common language, $\operatorname{lang}_{i j}$, and past colonial links, $c o l_{i j}$, such as $b_{i j}=d_{i s t_{i j}} c o l_{i j}$. Common language and colonial history appear crucial in explaining bilateral trade but direct measures are riddled with intrinsic errors. By using a constructed 0-1 index we limit the extent of these errors. In wine economics the importance of past colonial links has been studied for instance by Melonni and Swinnen (2014) who detail the rise and fall of Algeria as the largest wine-exporter, worldwide during the French colonization.

We use the OLS estimator, as well as the PPML and Gamma estimators 15 Using Monte Carlo simulations, Santos Silva and Tenreyro (2006) show that the Poisson pseudo-MLE performs better than the traditional OLS linear-in-logs. Head and Mayer (2013) recommend the use of OLS, Poisson and Gamma PML, and state that if the sample is large enough then Poisson and Gamma PML should give approximately the same result.

the impact of a pair-specific variable - such as distance or tariffs - the standard solution is to put in time-varying country-specific fixed effects. [...] Plainly we cannot use this approach to investigate the impact of using GDPs as the economic mass proxies'. We have also conducted estimations with different functional forms such as: 1) all variables concerning France (including price index) reported on the right hand side of the gravity equation (a trade adjusted measure) 2) fixed effects and the population variable are introduced on the left hand side to analyse whether the sign of population changes when multicollinearities between variables are reduced to the minimum 3 ) introduction of unit value of wines instead of price index. Whatever the specification, results reported in the text table are still valid.

${ }^{15}$ As recommended for instance by Head and Mayer (2013) who write "if all three estimates are similar, then we can relax because the model appears to be well specified [...] Therefore the OLS results are the maximum likelihood estimates". 


\begin{tabular}{|c|c|c|c|c|c|}
\hline Dep var: & \multicolumn{5}{|c|}{ French Wine Exportation (adjusted by french GDP per-capita) } \\
\hline Mode: & \multicolumn{3}{|c|}{ Air-plane } & Water-ship & Land-road \& rail \\
\hline Estimator: & OLS & PPML & Gamma & OLS & OLS \\
\hline \multirow[t]{2}{*}{ GDPs } & -0.007 & -0.012 & -0.034 & 0.290 & 0.385 \\
\hline & $(0.036)^{b}$ & $(0.028)$ & $(0.029)$ & $(0.007)^{a}$ & $(0.018)^{a}$ \\
\hline \multirow[t]{2}{*}{ POPs } & 0.083 & 0.116 & 0.075 & -0.063 & -0.115 \\
\hline & $(0.039)^{b}$ & $(0.027)^{a}$ & $(0.030)^{b}$ & $(0.009)^{a}$ & $(0.017)^{a}$ \\
\hline \multirow[t]{2}{*}{ Distance } & -0.105 & -0.001 & -0.143 & 0.108 & -0.180 \\
\hline & $(0.075)$ & $(0.064)$ & $(0.063)^{b}$ & $(0.009)^{a}$ & $(0.013)^{a}$ \\
\hline \multirow[t]{2}{*}{ CPIs } & -1.792 & -3.764 & -2.573 & -1.941 & 1.570 \\
\hline & $(1.779)$ & $(1.207)^{a}$ & $(1.474)^{a}$ & $(0.385)^{a}$ & $(0.724)^{b}$ \\
\hline \multirow[t]{2}{*}{ Colony } & -0.411 & -0.799 & -0.620 & 0.348 & -0.047 \\
\hline & $(0.102)^{a}$ & $(0.083)^{a}$ & $(0.081)^{a}$ & $(0.015)^{a}$ & $(0.044)$ \\
\hline \multirow[t]{2}{*}{ Common Language } & -0.661 & -0.192 & -0.448 & 0.155 & 0.332 \\
\hline & $(0.134)^{a}$ & $(0.118)$ & $(0.110)^{a}$ & $(0.019)^{a}$ & $(0.025)^{a}$ \\
\hline $\mathrm{R}^{2} /$ Pseudo $\mathrm{R}^{2}$ & 0.762 & 0.672 & 0.086 & 0.401 & 0.389 \\
\hline Obs & 3971 & 3971 & 3971 & 69079 & 39619 \\
\hline
\end{tabular}

Table 3: Gravity equation

Columns 1, 2 and 3 give results for wine exported by plane using the three different estimators. Distance and price index have the expected sign, but GDP and population contradict the theory. A positive sign is obtained for population, rejecting the idea that wines exported using this mode of transport are luxury goods. On the contrary, the theory is validated for wines exported by ship and road reported in Table 3 in column 4 and 5 using OLS. ${ }^{16}$ This validation of non-homothetic preferences is surprising since wines exported by road can be considered as basic goods not characterized by a strong income effect. After various robustness checks providing similar results, we conclude that these initial results are correct and that the theoretical model needed to be revisited. To reconcile our data with theory we decided to introduce economies of scale in transport. Depending on export-value, obviously firms pay different transport costs. There is a wide range of literature on this topic. For instance Skiba (2007) considering economies of scale in transport, finds that a $10 \%$ increase in the volume of trade brings about a $2.5 \%$ reduction in trade costs. Clark et al. (2004) find that transport costs are lower when trade volumes are high. In Kleinert and Spies (2011) total export figures determine the mode of transport. Transport costs of course vary with investment in

\footnotetext{
${ }^{16}$ We carried out estimations with Poisson and Gamma PML with similar results
} 
more efficient technology. By using price data from UPS, they find that a $10 \%$ increase in exports decreases transport prices by $0.8 \%$. Hummels, Lugovskyy and Skiba (2009) show that shipping costs decrease according to the number of competitors, with low tariffs and product prices and with high demand elasticities ${ }^{17}$ Lastly Rudolph (2009) demonstrates how a standard gravity equation can be biased if economies of scale in transport are not introduced.

By referring to this literature, we assume that transport costs take the following form:

$$
\tau_{i j}=\left(x_{i j, t}^{k}\right)^{\eta} d_{i j} e^{b_{i j}}
$$

where $x_{i j, t}^{k}$ represents the wine exports in value and $\eta$ density (dis)economies. There are economies of scale with $\eta$ negative, and diseconomies in the opposite case. Inserting this function in the gravity equation and resolving for $x_{i j, t}^{k}$ to eliminate the endogeneity bias gives:

$$
\begin{aligned}
\ln \left(x_{i j, t}^{k}\right)= & \frac{\alpha+\beta}{1-(1-\sigma) \eta} \ln \left(Y_{j, t} Y_{i, t}\right)+\frac{\beta}{1-(1-\sigma) \eta} \ln \left(L_{j, t} L_{i, t}\right)+\frac{(1-\sigma) \eta}{1-(1-\sigma) \eta} \ln \left(d_{i j} e^{b_{i j}}\right) \\
& +\frac{1}{1-(1-\sigma) \eta} \ln \left(P_{i, t} P_{j, t}\right)
\end{aligned}
$$

This last gravity equation is helpful in revisiting the previous results. In particular in comparison with Equation (7) the coefficient of distance now consists of the following parameters:

$$
\widehat{a_{3}}=\frac{(1-\sigma) \eta}{1-(1-\sigma) \eta}
$$

For air transport according to the estimation using the Gamma PML estimator we have $\widehat{a_{3}}=-0.143$, thus assuming an elasticity of substitution equal to 5 (which is a realistic value of $\sigma$ according to estimations of Broda and Weinstein, 2004), we obtain $\eta=-1.988$. From such a result we can now deduce $\beta$, we have:

$$
\widehat{a_{2}}=\frac{\beta}{1-(1-\sigma) \eta}
$$

\footnotetext{
${ }^{17}$ There also are interesting theoretical papers, for instance Duranton and Storper (2008) propose a model whereby the decrease in transport costs can generate an increase in trade costs. In their model with vertical differentiation and where the quality of input is not contractible, they show that a decrease in transport costs leads to exchange of higher quality goods for which trade costs increase. Lastly the assumption of endogenous transport costs with respect to trade is not innocuous in terms of specialization and location choice (see Matsuyama, 2007 and Behrens, Gaigné and Thisse, 2009, Behrens and Picard, 2011)
} 
and from Table (3. Gamma PML) the coefficient of population gives $\widehat{a_{2}}=0.075$ thus using $\eta$ and $\sigma$ we arrive at $\beta=-0.524$. This result confirms the income effect that was previously rejected. Lastly by using the coefficient of GDPs from:

$$
\widehat{a_{1}}=\frac{\alpha+\beta}{1-(1-\sigma) \eta}
$$

with $\widehat{a_{1}}=-0.034$ we get $\alpha=0.762$ which is relatively close to the unit elasticity of GDP obtained in many trade gravity equations. We note that our calculation of $\alpha$ and $\beta$ does not depend on existing estimations of $\sigma$. In other words these parameters only depend on our estimations in table (3). Resolving the system (8) 9 10 gives expressions of $(\eta, \beta, \alpha)$ where $\eta$ depends on $\sigma$ but where $\alpha$ and $\beta$ only depend on estimates:

$$
\eta=\frac{\widehat{a_{3}}}{\left(1+\widehat{a_{3}}\right)(1-\sigma)}, \quad \beta=\frac{\widehat{a_{2}}}{1+\widehat{a_{3}}}, \quad \alpha=\frac{\widehat{a_{1}}-\widehat{a_{2}}}{1+\widehat{a_{3}}}
$$

Table (4) summarizes the numerical expressions derived from estimations and also reports results for wine exported by road and ship since we expect a zero value for $\beta$ that was not obvious until now.

\begin{tabular}{lccc}
\hline Mode: & Air & Water & Land-road \& rail \\
\hline Transp econ scale $(\eta)$ & -1.988 & -0.024 & 0.054 \\
Income per cap $(\beta)$ & -0.524 & -0.056 & -0.140 \\
GDPs $(\alpha)$ & 0.762 & 0.318 & 0.609 \\
Calculation for $\eta$ using $\sigma=5$ & & &
\end{tabular}

Table 4: Economies of scale in transportation

Expected results are obtained. Wine exported by ship and road benefits from a smaller income effect than wine exported by air. The coefficient of $\beta$ is not strictly equal to zero but is however, closer to this value, in particular for wine transported by ship. Interestingly economies of scale are observed for transport by plane and ship $(\eta<0)$ but not for road. A $10 \%$ increase in the value of wine exported by road leads to a rise in transport costs of $0.5 \%$.

\section{Conclusion}

Hummels and Lugovskyy (2009) proposed a model generalizing the ideal variety approach of Lancaster $(1979,1984)$. In applying this model to the wine sector, we have 
confirmed the majority of its conclusions. A 1\% increase in GDP per capita generates, on average, an increase in price differential of between $0.55 \%$ and $1.13 \%$. Trade-share is strongly influenced by all variables approximating wealth concentration such as income earned at the top of the distribution. Lastly a gravity-trade equation supports the view that income effects play an important role in explaining wine exports but also raise questions about transport costs. Depending on economies of scale and market structure in this sector, changes in price and volume exported may partly be explained by transport costs interacting with rising global demand.

\section{References}

[1] Alvaredo, F., A. B. Atkinson, T. Piketty and E. Saez (2012), The World Top Incomes Database. Available at http://topincomes.gmond.parisschoolofeconomics.eu/

[2] Anderson, J. E. and E. Van Wincoop (2003), 'Gravity with Gravitas : A Solution to the Border Puzzle', American Economic Review, 93, 1, 170-192.

[3] Ashenfelter, O. (2008), 'Predicting the Quality and Prices of Bordeaux Wine', The Economic Journal, 118, 529, F174-F184.

[4] Baldwin, R. and D. Taglioni (2007), 'Gravity for Dummies and Dummies for Gravity Equations', NBER Working Paper No. 12516 (Cambridge, MA: National Bureau of Economic Research).

[5] Baldwin, R. and D. Taglioni (2014), 'Gravity Chains: Estimating Bilateral Trade Flows When Parts And Components Trade Is Important', Journal of Banking and Financial Economics, 2, 2, 61-82.

[6] Barclays (2012), 'Profit or Pleasure? Exploring the motivations behind treasure trends', Wealth Insights, Volume 15.

[7] Behrens, K., C. Gaigné and J.-F. Thisse (2009), 'Industry location and welfare when transport costs are endogenous', Journal of Urban Economics, 65, 2, 195208.

[8] Behrens, K. and P. M. Picard (2011), 'Transportation, Freight Rates, and Economic Geography', Journal of International Economics, 85, 2, 280-291. 
[9] Bekkers, E., J. Francois and M. Manchin (2012), 'Import Prices, Income, and Inequality', European Economic Review, 56, 4, 848-869.

[10] Bergstrand, J. H. (1989), 'The Generalized Gravity Equation, Monopolistic Competition, and the Factor-Proportions Theory in International Trade', The Review of Economics and Statistics, 71, 1, 143-153.

[11] Broda, C. and D. E. Weinstein (2004), 'Globalization and the Gains from Variety', NBER WP 10314 (Cambridge, MA)

[12] Cardebat, J.-M., J.-M. Figuet and E. Paroissien (2014), 'Expert Opinion and Bordeaux Wine Prices: An Attempt to Correct Biases of Subjective Judgments', Journal of Wine Economics, 9, 3, 282-303.

[13] Clark, X., D. Dollar and A. Micco (2004), 'Port Efficiency, Maritime Transport Costs, and Bilateral Trade', Journal of Development Economics, 75, 2, 417-450.

[14] Chevet, J.-M., S. Lecocq and M. Visser (2011), 'Climate, Grapevine Phenology, Wine Production and Prices: Pauillac (1800-2009)', The American Economic Review: Papers and Proceedings, 101, 3, 142-146.

[15] Combris, P., S. Lecocq and M. Visser (1997), 'Estimation of a Hedonic Price Equation for Bordeaux Wine : Does Quality Matter ?', The Economic Journal, 107, 441, 390-402.

[16] Crozet, M., K. Head and T. Mayer (2012), 'Quality Sorting and Trade: Firm-level Evidence for French Wine', The Review of Economic Studies, 79, 2, 609-644.

[17] Di Comite, F., J.-F. Thisse and H. Vandenbussche (2014), 'Verti-zontal differentiation in export markets', Journal of International Economics, 93, 1, 50-56.

[18] Dimson E., P. L. Rousseau and C. Spaenjers (2015), 'The Price of Wine', Journal of Financial Economics, 118, 2, 431-449.

[19] Duranton, G. and M. Storper (2008), 'Rising trade costs? Agglomeration and trade with endogenous transaction costs', Canadian Journal of Economics, 41, 1, 292-319. 
[20] Fajgelbaum, P., G. M. Grossman and E. Helpman (2011), 'Income Distribution, Product Quality, and International Trade', Journal of Political Economy, 119, 4, 721-765.

[21] Frankel, J. A., E. Stein, and S.-J.Wei (1998), 'Continental Trading Blocs: Are They Natural or SuperNatural ?', in J. Frankel (ed.), The Regionalization of the World Economy (Chicago : University of Chicago Press).

[22] Gergaud, O. and V. Ginsburgh (2008), 'Natural Endowments, Production Technologies and the Quality of Wines in Bordeaux. Does Terroir Matter?', The Economic Journal, 118, 529, F142-F157.

[23] Head, K. and T. Mayer (2013), 'What separates us? Sources of resistance to globalization', Canadian Journal of Economics, 46, 4, 1196-1231.

[24] Hummels, D. and V. Lugovskyy (2009), 'International Pricing in a Generalized Model of Ideal Variety', Journal of Money, Credit and Banking, 41, 3-33.

[25] Hummels, D., V. Lugovskyy and A. Skiba (2009), 'The trade reducing effects of market power in international shipping', Journal of Development Economics, 89, $1,84-97$.

[26] Jackson, L. F. (1984), 'Hierarchic Demand and The Engel Curve for Variety', The Review of Economics and Statistics, 66, 1, 8-15.

[27] Kleinert, J. and J. Spies (2011), 'Endogenous Transport Costs in International Trade', IAW Discussion Papers No. 74 (Tübigen : Institute for Applied Economic Research at the University of Tübigen).

[28] Krugman, P. (1980), 'Scale Economies, Product Differenciation, and the Patterns of Trade', American Economic Review, 70, 5, 950-959.

[29] Lancaster, K. (1979), 'Variety, Equity, and Efficiency', New York: Columbia University Press.

[30] Lancaster, K. (1984), 'Protection and Product Differentiation', in H. Kierzkowski (ed.), Monopolistic Competition and International Trade (Oxford: Oxford University Press). 
[31] Markusen, J. R. (2010), 'Putting Per-Capita Income Back into Trade Theory', NBER WP 15903 (Cambridge, MA).

[32] Matsuyama, K. (2007), 'Beyond Icebergs: Towards a Theory of Biased Globalization', The Review of Economic Studies, 74, 1, 237-253.

[33] Melitz, M. J. and G. I. P. Ottaviano (2008), 'Market Size, Trade and Productivity', Review of Economic Studies, 75, 1, 295-316.

[34] Meloni, G. and J. Swinnen (2014), 'The Rise and Fall of the World's largest Wine Exporter - And Its Institutional Legacy', Journal of Wine Economics, 9, 1, 3-33.

[35] Millar, R. (2014), 'Liv-ex launches Fine Wine 1000 index', The Drinks Business. Available at https://www.thedrinksbusiness.com.

[36] Nerlove M. (1995), 'Hedonic Price Functions and the Measurement of Preferences: The Case of Swedish Wine Consumers', European Economic Review, 39, 9, 16971716 .

[37] Roma, P., G. Di Martino and G. Perrone (2013), 'What to show on the wine labels: a hedonic analysis of price drivers of sicilian wines', Applied Economics, 45, 19, $2765-2778$.

[38] Rudolph, S. (2009) , 'The Gravity Equation with Micro-founded Trade Costs', Dresden Discussion Paper in Economics No. 11/09 (Dresden : Dresden University of Technology, Faculty of Business and Economics, Department of Economics).

[39] Santos Silva, J. M. C. and S. Tenreyro (2006), 'The Log of Gravity', The Review of Economics and Statistics, 88, 4, 641-658.

[40] Sauré, P. (2012), 'Bounded Love of Variety and Patterns of Trade', Open Economies Review, 23, 4, 645-674.

[41] Simonovska, I. (2015), 'Income Differences and Prices of Tradables: Insights from an Online Retailer', Review of Economic Studies, 82, 4, 1612-1656.

[42] Skiba, A. (2007), 'Regional Economies of Scale in Transportation and Regional Welfare', Working Paper Series in Theoretical and Applied Economics No. 200705 (University of Kansas, Department of Economics) 
[43] Storchmann, K. (2011), 'Wine Economics: Emergence, Developments, Topics', Agrekon, 50, 3, 1-28.

[44] Verhoogen, E. (2008), 'Trade, Quality Upgrading and Wage Inequality in the Mexican Manufacturing Sector', Quaterly Journal of Economics, 123, 2, 489-530.

\section{Appendix A: Price elasticity and geographical reputa- tion}

To investigate whether the previous results hold at a more disaggregated level, we pursue the econometric exercise by focusing on French regional wines. This decision was taken in order to treat specific heterogeneous behaviour not fully captured by fixed effect and/or to consider aggregation bias. By estimating the previous equation with firm and time fixed effects and by separating wine by region we can compare the effects of both competition and income on wines produced in different locations.

We consider three regions: Bordeaux, Alsace and Languedoc Roussillon.

Bordeaux is recognized worldwide for its wine and the wines produced there have the most prestigious reputation in our sample.

We chose Alsace as a region producing white wines with a clear differentiation including the reputable dry Riesling and Gewürztraminer wines. This region also has the advantage of being located near the urbanisation corridor of Western Europe, with a population of around 111 million, offering producers an advantage in terms of market access.

Lastly, we consider the Languedoc Roussillon region which is one of the main wine producers in France, with annual production volumes that have been known to surpass the production of nations like the United States. However the production is heterogeneous in terms of quality and the region suffers from a poorer reputation than wines produced elsewhere (e.g. in Bordeaux).

Table (5) presents the results. It is worth noting that while Hummels and Lugovskyy (2009) pool over multiple exporters and provide results at an industrial level (HS2), we have enough data variation to lead the estimation at the HS8 level maintaining firmfixed effects. This detailed analysis confirms the previous results, a rise in GDP per capita favours wine exportation for many varieties, while GDP growth, theoretically associated with more competition, is detrimental. 


$\begin{array}{lcccc}\text { Wine } & \text { Bordeaux } & \text { Alsace } & \text { Lang Rous } & \text { Not AOC or PGI } \\ \text { GDP per capita } & 1.26 & 1.88 & 1.63 & 1.15 \\ & (0.706)^{c} & (0.971)^{c} & (0.506)^{a} & (0.322)^{a} \\ \text { GDP } & -0.85 & -1.97 & -1.52 & -1.03 \\ & (0.676) & (0.970)^{b} & (0.429)^{a} & (0.318)^{a} \\ \text { Year fixed effect } & \text { Yes } & \text { Yes } & \text { Yes } & \text { Yes } \\ \text { Firms fixed effect } & \text { Yes } & \text { Yes } & \text { Yes } & \text { Yes } \\ \text { R-square } & 0.16 & 0.08 & 0.13 & 0.03 \\ \text { Obs } & 13506 & 3514 & 4648 & 17734 \\ \text { OLS with RSE in brackets corrected by clusters on destination market. } & \\ \text { a: significant at 1\%, b: significant at 5\%, c: significant at 10\% } \\ \text { All variables are in Log }\end{array}$

Table 5: Price regressions for French wines

Interestingly, for Bordeaux wines the coefficient of market size is insignificant, indicating that competition is less fierce for these wines. This result supports the GMIV model, extended to take into account reputational effects which can neutralize the effect of competition. The total effect of per capita GDP growth, only depends therefore on $a_{2}$ in Equation (1) and is equal to 1.26, which is clearly the strongest impact. For wines produced in Alsace and in Languedoc Roussillon the total effect is of $\widehat{a}_{1}+\widehat{a}_{2}=-0.09$ and of 0.11 respectively. The negative total effect for Alsace wines is worth noting since it has never previously been obtained and indicates that the total effect of per capita GDP growth can increase price elasticity. A vast majority of wines produced in these regions are products benefitting from labels such as the AOC classification (Appelation d'Origine Contrôlée) or PGI (Protected Geographical Indication) providing a positive effect on the reputation of these wines. The last column of Table (5) confirms that conclusions of the GMIV model also hold for wines without AOC and PGI classifications.

\section{Appendix B: data}




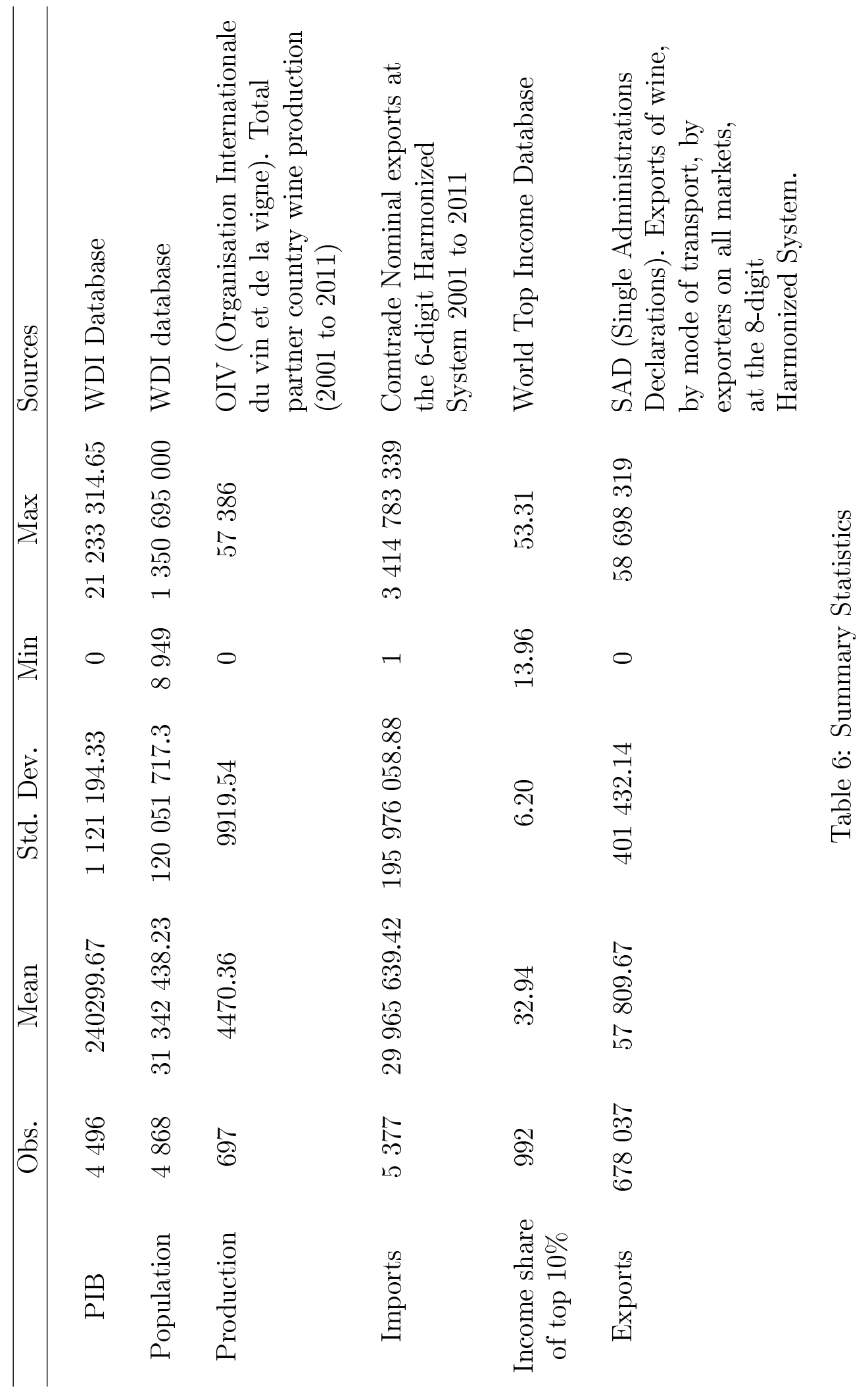

